\title{
Himenópteros parasitóides (Insecta, Hymenoptera) coletados em cultura de algodão (Gossypium hirsutum L.) (Malvaceae), no município de Ribeirão Preto, SP, Brasil
}

\author{
Nelson Wanderley Perioto ${ }^{1}$ \\ Rogéria Inês Rosa Lara ${ }^{1}$ \\ José Carlos Carvalho dos Santos ${ }^{1}$ \\ Aline Selegatto ${ }^{2}$
}

\begin{abstract}
Parasitoid Hymenoptera (Insecta, Hymenoptera) collected in a cotton (Gossypium hirsutum L.) (Malvaceae) plantation at the municipal district of Ribeirão Preto, SP, Brazil. Parasitoid Hymenoptera were collected by using Moericke trap placed in a cotton plantation (Gossypium hirsutum L.) of the variety Delta Pine 90, during the period of February $23^{\text {rd }}$ to April $3^{\text {rd }}, 2001$. A total of 16,166 specimens of parasitoids, belonging to eight superfamilies and 22 families, were collected. Encyrtidae, Trichogrammatidae, Mymaridae and Scelionidae were the most common families, being responsible for $45.14 \%, 19.11 \%, 14.33 \%$ and $6.57 \%$ of the total number of parasitoids collected, respectively. Other eigthteen families showed the relative frequency lower than $5 \%$.
\end{abstract}

KeYwords. Brazil; cotton; Hymenoptera; parasitoids; survey.

\section{INTRODUÇÃO}

Os himenópteros parasitóides são um importante elemento da fauna neotropical por seu papel no controle da população de outros insetos interferindo, direta ou indiretamente, e de forma ainda não bem quantificada, nas cadeias tróficas de grande parte dos ecossistemas terrestres. Por regular as populações de outros insetos, muitas espécies de himenópteros parasitóides são utilizadas no controle biológico e/ou integrado de pragas agrícolas com sucesso.

Hanson \& GaUld (1995) afirmam que os himenópteros parasitóides são compostos por, aproximadamente, 115.000 espécies e estimam que tal número possa chegar a 250.000 .

A despeito da vasta bibliografia existente sobre este grupo abordando principalmente aspectos de sua taxonomia e biologia, poucos autores têm se dedicado a realizar estudos a respeito de sua composição faunística (AzEvedo \& SANTos 2000). Noyes (1989) e HANSON \& GAULD (1995) realizaram levantamentos deste grupo de insetos na Indonésia e na Costa Rica, respectivamente, enquanto PeRIOTO (1991), em área de vegetação de cerrado e AzEvEDo \& SANTos (2000), em área de
Mata Atlântica, realizaram estudos semelhantes no Brasil. No entanto, pouco se conhece a respeito da composição faunística em agroecossistemas, o que justifica a realização deste estudo que teve por objetivo conhecer as famílias de himenópteros parasitóides em uma cultura de algodão e suas frequiências relativas.

\section{MATERIALEMÉTODOS}

Este ensaio foi realizado em uma cultura de algodão (Gossypium hirsutum L.) da variedade Delta Pine 90, em uma área de $3.500 \mathrm{~m} 2\left(21^{\circ} 11^{\prime} 11^{\prime \prime} \mathrm{S} ; 47^{\circ} 51^{\prime} 44^{\prime \prime} \mathrm{O}\right)$, pertencente ao Instituto de Zootecnia da Secretaria de Agricultura e Abastecimento do Estado de São Paulo, em Ribeirão Preto, SP, Brasil, no período de 23 de fevereiro a 3 de abril de 2001. A cultura, semeada no início do mês de dezembro de 2000, com espaçamento de 1,0 m entre linhas estava, quando do início do experimento, no início do florescimento (estágio 3). As coletas dos himenópteros parasitóides foram realizadas em 23 e 28 de fevereiro, 5, 9, 13, 21 e 27 de março e 3 de abril de 2001, através de 84 aparatos de coleta adaptados por Ревіото et al. (2000).

1. Instituto Biológico, Laboratório de Sanidade Animal e Vegetal de Ribeirão Preto. Rua Peru, 1472-A, 14075-310 Ribeirão Preto-SP, Brasil. Endereço eletrônico: nperioto@biologico.br

2. Estagiária, graduanda em Ciências Biológicas no Centro Universitário "Barão de Mauá". Rua Ramos de Azevedo, 423, 14090-180 Ribeirão Preto-SP, Brasil. 
Tabela 1. Número de himenópteros parasitóides coletados nas armadilhas superiores e inferiores, seu total e suas freqüências relativas em cultura de algodoeiro, na safra 2000/2001, em Ribeirão Preto (SP).

\begin{tabular}{|c|c|c|c|c|c|c|c|c|c|c|c|}
\hline & $\mathbf{S}$ & I & $\mathbf{T}$ & FRS & FRI & FRPS & FRPI & FRPS+I & FRSS & FRSI & FRSS+I \\
\hline Chrysidoidea & 56 & 70 & 126 & 44,44 & 55,56 & 0,35 & 0,43 & 0,78 & & & \\
\hline Chrysididae & 6 & 3 & 9 & 66,67 & 33,33 & 0,04 & 0,02 & 0,06 & 4,76 & 2,38 & 7,14 \\
\hline Bethylidae & 50 & 67 & 117 & 42,74 & 57,26 & 0,31 & 0,41 & 0,72 & 39,68 & 53,17 & 92,86 \\
\hline Chalcidoidea & 7511 & 6209 & 13720 & 54,74 & 45,26 & 46,46 & 38,41 & 84,87 & & & \\
\hline Aphelinidae & 153 & 210 & 363 & 42,15 & 57,85 & 0,95 & 1,30 & 2,25 & 1,12 & 1,53 & 2,65 \\
\hline Eulophidae & 165 & 130 & 295 & 55,93 & 44,07 & 1,02 & 0,80 & 1,82 & 1,20 & 0,95 & 2,15 \\
\hline Encyrtidae & 4305 & 2992 & 7297 & 59,00 & 41,00 & 26,63 & 18,51 & 45,14 & 31,38 & 21,81 & 53,19 \\
\hline Eurytomidae & 7 & 10 & 17 & 41,18 & 58,82 & 0,04 & 0,06 & 0,11 & 0,05 & 0,07 & 0,12 \\
\hline Chalcididae & 47 & 38 & 85 & 55,29 & 44,71 & 0,29 & 0,24 & 0,53 & 0,34 & 0,28 & 0,62 \\
\hline Mymaridae & 955 & 1362 & 2317 & 41,22 & 58,78 & 5,91 & 8,43 & 14,33 & 6,96 & 9,93 & 16,89 \\
\hline Pteromalidae & 121 & 109 & 230 & 52,61 & 47,39 & 0,75 & 0,67 & 1,42 & 0,88 & 0,79 & 1,68 \\
\hline Signiphoridae & 7 & 8 & 15 & 46,67 & 53,33 & 0,04 & 0,05 & 0,09 & 0,05 & 0,06 & 0,11 \\
\hline Torymidae & 8 & 3 & 11 & 72,73 & 27,27 & 0,05 & 0,02 & 0,07 & 0,06 & 0,02 & 0,08 \\
\hline Trichogrammatidae & 1743 & 1347 & 3090 & 56,41 & 43,59 & 10,78 & 8,33 & 19,11 & 12,70 & 9,82 & 22,52 \\
\hline \multicolumn{12}{|l|}{ Cynipoidea } \\
\hline Eucoilidae & 224 & 120 & 344 & 65,12 & 34,88 & 1,39 & 0,74 & 2,13 & & & \\
\hline Platygastroidea & 555 & 586 & 1141 & 48,64 & 51,36 & 3,43 & 3,62 & 7,06 & & & \\
\hline Scelionidae & 523 & 539 & 1062 & 49,25 & 50,75 & 3,24 & 3,33 & 6,57 & 45,84 & 47,24 & 93,08 \\
\hline Platygasteridae & 32 & 47 & 79 & 40,51 & 59,49 & 0,20 & 0,29 & 0,49 & 2,80 & 4,12 & 6,92 \\
\hline Ichneumonoidea & 134 & 281 & 415 & 32,29 & 67,71 & 0,83 & 1,74 & 2,57 & & & \\
\hline Braconidae & 58 & 85 & 143 & 40,56 & 59,44 & 0,36 & 0,53 & 0,88 & 13,98 & 20,48 & 34,46 \\
\hline Ichneumonidae & 76 & 196 & 272 & 27,94 & 72,06 & 0,47 & 1,21 & 1,68 & 18,31 & 47,23 & 65,54 \\
\hline Ceraphronoidea & 151 & 149 & 300 & $\mathbf{5 0 , 3 3}$ & 49,67 & 0,93 & 0,92 & 1,86 & & & \\
\hline Proctotrupoidea & 58 & 51 & 109 & 53,21 & 46,79 & 0,36 & $\mathbf{0 , 3 2}$ & 0,67 & & & \\
\hline Diapriidae & 47 & 48 & 95 & 49,47 & 50,53 & 0,29 & 0,30 & 0,59 & 43,12 & 44,04 & 87,16 \\
\hline Proctotrupidae & 11 & 3 & 14 & 78,57 & 21,43 & 0,07 & 0,02 & 0,09 & 10,09 & 2,75 & 12,84 \\
\hline \multicolumn{12}{|l|}{ Evanioidea } \\
\hline$\underline{\text { Evaniidae }}$ & 7 & 4 & 11 & 63,64 & 36,36 & 0,04 & 0,02 & 0,07 & & & \\
\hline Total parasitóide & 8696 & 7470 & 16166 & 53,79 & 46,21 & & & & & & \\
\hline
\end{tabular}

S e I= número de himenópteros parasitóides coletados nas armadilhas superiores (AS) e inferiores (AI), respectivamente; T= $\Sigma$ S+I; FRS e FRI= freqüência relativa dos himenópteros parasitóides nas AS e AI, respectivamente; FRPS e FRPI= frequiências relativas das superfamílias e famílias de himenópteros parasitóides coletados nas AS e AI, respectivamente, em relação ao total de himenópteros parasitóides coletados; FRPS+I= $\Sigma$ FRPS+FRPI; FRSS e FRSI= freqüências relativas das famílias de himenópteros parasitóides coletados nas AS e AI, respectivamente, em relação ao total de himenópteros parasitóides da superfamília a que pertencem; FRSS+I= $\Sigma$ FRSS+FRSI.

Estes aparatos são compostos por duas armadilhas de Moericke (pratos fundos amarelos, descartáveis, de $12 \mathrm{~cm}$ de diâmetro) dispostas a 0,5 e $1,0 \mathrm{~m}$ de altura, de forma que as bandejas superiores ficaram à altura aproximada do dossel da cultura. Os aparatos de coleta foram distribuídos em 4 linhas distantes $8 \mathrm{~m}$ entre si e, em cada linha foram estabelecidos 21 pontos de amostragem, distantes $5 \mathrm{~m}$ entre si. Os himenópteros parasitóides foram mantidos em álcool a 70\% e identificados em nível de família segundo Goulet \& Huber (1993) e Grissel $\&$ SHAUFF (1990). Dada a ocorrência de pragas que ameaçavam a continuidade do experimento, foi realizada uma aplicação de inseticidas em seis de março de 2001.

O material coletado foi depositado na Coleção Entomológica “Adolph Hempel” do Instituto Biológico, de São Paulo.

\section{RESULTADOSEDISCUSSÃO}

Foram coletados 16.166 himenópteros parasitóides pertencentes a 22 famílias, distribuídas em oito superfamílias (Tabela 1): Chalcidoidea, Platygastroidea, Ichneumonoidea, Cynipoidea, Ceraphronoidea, Chrysidoidea, Proctotrupoidea e Evanioidea. As famílias mais abundantes foram Encyrtidae, Trichogrammatidae, Mymaridae e Scelionidae que representaram $45,14 \%, 19,11 \%, 14,33 \%$ e $6,57 \%$ do número total de himenópteros parasitóides coletados, respectivamente. As dezoito famílias restantes apresentaram frequiências relativas inferiores a $5 \%$.

Azevedo \& Santos (2000) coletaram 8.305 himenópteros parasitóides pertencentes a 30 famílias através de varredura da 


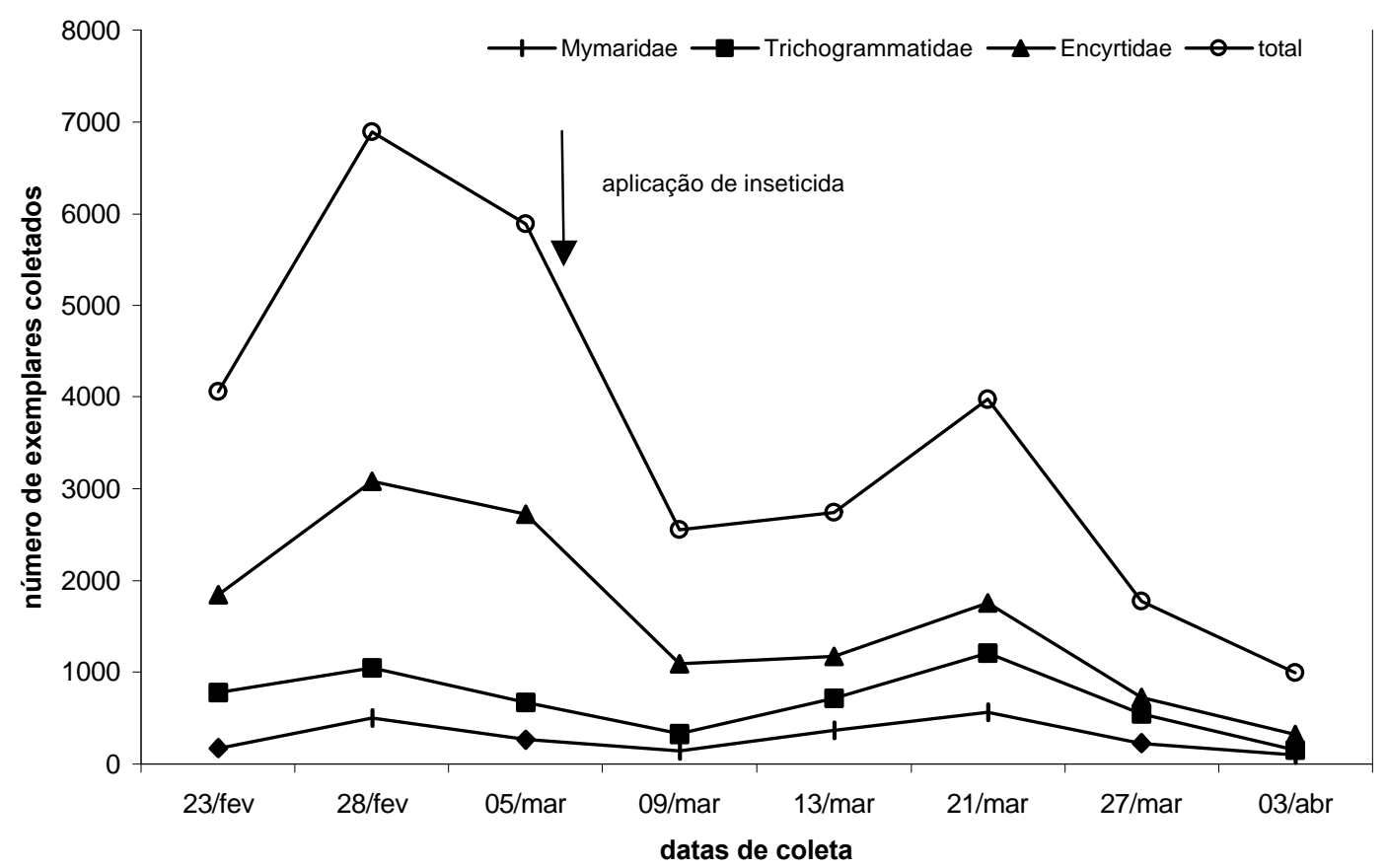

Fig. 1. Total de himenópteros parasitóides, Mymaridae, Encyrtidae e Trichogrammatidae (Chalcidoidea) coletados em cultura do algodoeiro na safra 2000/2001, em Ribeirão Preto, SP.

vegetação, em uma área de Mata Atlântica Ombrófila Densa, em Cariacica, Espírito Santo. As famílias mais freqüentes por eles capturadas foram Scelionidae, Braconidae e Eucoilidae que representaram $21,78 \%, 14,53 \%$ e $12,42 \%$, respectivamente, do total de himenópteros parasitóides amostrados. A diferença no número de famílias capturadas e nas frequiências relativas observadas no presente estudo e no estudo de AzEvedo \& SAntos (2000) é resultado da estrutura dos ecossistemas envolvidos e retrata a menor riqueza de famílias de himenópteros parasitóides que ocorrem no agroecossistema da cultura do algodão.

Noyes (1989), em um estudo faunístico das famílias de himenópteros parasitóides na floresta tropical úmida da Indonésia, utilizando cinco métodos de coleta, obteve 39 famílias de parasitóides, número próximo àquele encontrado por PеRioto (1991), 31 famílias, em uma área de vegetação de cerrado com pouca ação antrópica, utilizando também cinco tipos de armadilhas em São Carlos, SP.

Na superfamília Chalcidoidea destacaram-se as famílias Encyrtidae, Trichogrammatidae e Mymaridae (Fig. 1). Na família Encyrtidae observou-se que uma única espécie não identificada do gênero Copidosoma Ratzeburg, 1844, representou 94,18\% do total dos 7.297 encirtídeos capturados. Provavelmente, esta espécie é responsável por parte do controle natural da população de lagartas que ocorrem naquela cultura.

Trichogrammatidae e Mymaridae são parasitóides de ovos de outros insetos e representaram, conjuntamente, $33,44 \%$ do total de himenópteros parasitóides coletados. A alta freqüência relativa dessas famílias pode ser atribuída à existência de um grande número de hospedeiros potenciais das mesmas na cultura em questão. A título de exemplo, podemos citar, para o Brasil, a ocorrência de Trichogramma pretiosum Riley, 1879, que tem como hospedeiros ovos de Heliothis virescens (Fabricius, 1781), Allabama argilacea (Huebner, 1818) e Pectinophora gossypiella Saunders, 1844, pragas do algodoeiro (RAMAlHo 1994).

Na superfamília Platygastroidea destacou-se a família Scelionidae (6,57\% dos himenópteros parasitóides coletados). Tendo em vista que os selionídeos são endoparasitóides de ovos de outros insetos e de alguns outros artrópodes (GAULD \& Bolton 1988) esta família, assim como Mymaridae e Trichogrammatidae, atua como importante agente controlador de populações de insetos-praga da cultura do algodão.

As demais superfamílias coletadas tiveram freqüências relativas inferiores a 5\%, destacando-se as famílias Eucoilidae (Cynipoidea), Ichneumonidae e Braconidae (Ichneumonoidea) e Bethylidae (Chrysidoidea) com 2,13\%, 1,68\%, 0,88\% e 0,72\%, respectivamente, do total de himenópteros parasitóides coletados.

Do total dos himenópteros parasitóides coletados, 53,79\% foram capturados nas armadilhas de Moericke instaladas a $1 \mathrm{~m}$ do solo (doravante grafadas como AS), enquanto que $46,21 \%$ o foram nas armadilhas instaladas a $0,5 \mathrm{~m}$ do solo (doravante grafadas como AI). O padrão observado para o total dos himenópteros parasitóides foi mantido em Chalcidoidea (54,74\% nas AS e 45,26\% nas AI), Cynipoidea (65,12\% e $34,88 \%)$, 
Ceraphronoidea (50,33\% e 49,67\%), Proctotrupoidea (53,21\% e $46,79 \%$ ) e Evanioidea (63,64\% e 36,36\%). Chrysidoidea, Platygastroidea e Ichneumonoidea apresentaram maior número de exemplares coletados nas AI com 44,44\% e 55,56; 48,64\% e $51,36 \%$; e 32,29\% e 67,71\%, respectivamente. À exceção de Ichneumonoidea, Cynipoidea e Evanioidea que conjuntamente representaram $4,77 \%$ do total de himenópteros parasitóides coletados, todas as superfamílias apresentaram índices de distribuição altitudinal próximos a $50 \%$.

Dentre os Chalcidoidea, Aphelinidae, Eurytomidae, Mymaridae e Signiphoridae apresentaram maior número de exemplares capturados nas AI.

Observou-se que após a aplicação de inseticidas realizada no dia seis de março de 2001, ocorreu uma drástica redução da população de himenópteros parasitóides (Fig. 1). Esta comunidade apresentou sinais de recuperação na amostragem realizada em 13 de março, o que se confirmou na amostragem do dia 21 daquele mês. No final do mês de março e no início do mês de abril de 2001, ocorreu intensa precipitação pluvial na área de estudo o que impediu a análise das coletas realizadas nos dias 27 de março e 3 de abril.

Agradecimentos. À FMC do Brasil Indústria e Comércio S.A., pelo suporte financeiro.

\section{REFERÊNCIAS}

Azevedo, C. O. \& H. S. Santos. 2000. Perfil da fauna de himenópteros parasitóides (Insecta, Hymenoptera) em uma área de Mata Atlântica da Reserva Biológica de Duas Bocas, Cariacica, ES, Brasil. Boletim do Museu de Biologia Mello Leitão, série nova, 11/12: 116126.

Gauld, I. D. \& B. Bolton. 1988. The Hymenoptera. Oxford, Oxford University Press, $332 \mathrm{p}$.

Goulet, H. \& J. T. Huber (eds.). 1993. Hymenoptera of the world: an identification guide to families. Ottawa, Agriculture Canada Publication, vii $+668 \mathrm{p}$.

Grissell, E. E. \& M. E. Shauff. 1990. A handbook of the families of Neotropical Chalcidoidea (Hymenoptera). Washington-DC, Entomological Society of Washington, $85 \mathrm{p}$.

Hanson, P. E. \& I. D. Gauld (eds.). 1995. The Hymenoptera of Costa Rica. Oxford, Oxford University Press, xvii $+893 p$.

Noyes, J. S. 1989. A study of five methods of sampling Hymenoptera (Insecta) in a tropical rainforest with special reference to the Parasitica. Journal of Natural History 23: 285-298.

Perioto, N. W. 1991. Perfil da fauna de Hymenoptera Parasitica, incluindo Chrysidoidea, do cerrado da Fazenda Canchim (EMBRAPA, São Carlos, SP). Dissertação de Mestrado, UFSCar, São Carlos, $70 \mathrm{p}$.

Perioto, N. W.; R. I. R. Lara; J. C. C. Santos \& T. C. Da Silva. 2000. Utilização de armadilhas de Möericke em ensaios de seletividade de inseticidas em himenópteros parasitóides. Arquivos do Instituto Biológico 67(supl.): 93.

Ramalho, F. S. 1994. Cotton pest manegement: part 4. A brazilian perspective. Annual Review of Entomology 39: 563-578. 